\title{
Aspectos da Política Nacional de Saneamento diante da transição democrática da sociedade e do Estado brasileiro
}

\section{Brazilian National Sanitation Policy Aspects Opposite the Democratic Transition of State and Society in Brazil}

\author{
Ricardo Silva GAMA*
}

\begin{abstract}
RESUMO
Apresenta-se um breve estudo sobre a Política Nacional de Saneamento, mediante exposição de um panorama do regime da antiga Lei n. ${ }^{\circ} 5.318 / 67$ em comparação com aquele trazido pela nova política pública do setor, consubstanciada na Lei n. ${ }^{\circ} 11.445 / 2007$. Puderam ser extraídos da pesquisa alguns elementos que apontam um impulso participativo na nova legislação, contudo, de modo ainda tímido diante das possibilidades que se encontravam nas mãos dos gestores desta política pública. Após, busca-se incursão e rápida análise acerca dos dados relativos ao esgotamento sanitário em âmbitos nacional, regional e local, extraindo-se as conclusões que se entenderam pertinentes, no sentido de que a política sanitária nacional, de modo geral, encontra precária implementação, especialmente considerando-se os dados obtidos na bacia hidrográfica do litoral do Paraná.
\end{abstract}

Palavras-chave: política de saneamento; participação e democracia; efetividade; bacia hidrográfica do litoral do Paraná.

\begin{abstract}
This article presents a short study about the Brazilian National Sanitation Policy with an overview of the former Act 5.318/67 in parallel with the new public policy of the sector, carried by the Act 11.445/2007. Some elements could be extracted from the research that indicates a participative impulse in the new law; however, they are still timid against the real possibilities that were in the hands of the managers of this public policy. In a second moment, this work presents some of the national, regional and local sanitary data, coming to pertinent conclusions that indicate, in general, the precarious level of implementation of the national sanitation policy in Brazil, especially considering the local data obtained in the coastline basin of Paraná.
\end{abstract}

Key-works: sanitation policy; participation and democracy; effectivity; coastline basin of Paraná. 


\section{Introdução}

Embora já se faça consolidada institucionalmente há mais de 3 (três) anos, a "nova" Política Nacional de Saneamento ainda é pouco estudada em âmbito acadêmico no Brasil. E a análise da evolução desta política pública está vinculada à mudança de perspectiva do Estado e da sociedade brasileiros, que, em meados da década de 1980, passaram por uma transição democrática ainda em fase de consolidação, o que teve inegável influência na questão do saneamento.

Em vista do quadro de transição apresentado e das perspectivas que se apresentam acerca do tema, o intuito do presente trabalho é apresentar, de forma crítica, uma análise acerca da efetividade da implementação da Política Nacional de Saneamento nas perspectivas preventiva e promocional (SOUZA et al., 2007) - trazida no corpo da Lei n. ${ }^{\circ} 11.445 / 2007$-, utilizando, para tanto, dados obtidos em uma visão nacional, regional e local (onde há confronto das informações de cunho geral com aquelas obtidas no âmbito da bacia hidrográfica litorânea do Estado do Paraná).

O ponto de partida do estudo busca uma comparação entre o modelo de gestão trazido na norma acima indicada e o modelo adotado anteriormente pela antiga Lei $\mathrm{n}^{\circ}$ 5.318/1967. A partir desta perquirição, pretende-se averiguar a efetividade de aplicação da nova Política Nacional de Saneamento a partir da apreensão e análise de dados fornecidos por órgãos públicos, alguns ambientais e de recursos hídricos, além de agentes do mercado de prestação de serviços sanitários, os quais serão explicitados oportunamente.

Justifica-se a perquirição ora desenvolvida na medida em que o saneamento tem reflexos imediatos nos temas de saúde pública e meio ambiente, tratando-se de um dos principais pontos sensíveis para efetivação dos direitos humanos e sociais no Estado brasileiro.

\section{Dados locais: a Bacia Hidrográfica do Litoral do Paraná}

Os dados locais, neste caso, têm o potencial de indicar o grau de implementação da política sanitária em âmbito na- cional, haja vista que, com relação ao Estado do Paraná e aos municípios que integram sua bacia hidrográfica litorânea, inexiste qualquer política regional ou local de saneamento, aplicando-se de forma direta a regulamentação nacional.

O Paraná tem seu território dividido em 16 (dezesseis) grandes bacias hidrográficas (SUDERHSA, 2009), dentre as quais a Bacia Litorânea, que se estende para além dos municípios integrantes do litoral paranaense ${ }^{1}$, abrangendo corpos d'água que nascem na cabeceira da serra do mar, ainda nos Municípios de Quatro Barras, Piraquara, São José dos Pinhais, Tijucas do Sul, Campina Grande do Sul e Bocaiúva do Sul (onde se encontram seus divisores de águas), com desemboque no Oceano Atlântico. Verifica-se assim que a bacia litorânea do Paraná não compreende exatamente a zona costeira do Estado ${ }^{2}$, estendendo-se além de seus limites.

As unidades de paisagem "Serra do Mar" e "litoral" correspondem a cerca de 5\% do relevo do Estado do Paraná, as quais concentram grande parte da diversidade ambiental da região, com ocorrência de morros e serras de até $1.600 \mathrm{~m}$ de altitude, remanescentes de planaltos, planícies e leques aluviais, planícies costeiras, grandes ilhas e complexos estuarinos (PIERRI et al., 2006, p. 139). Com relação às formações geológicas, a bacia do litoral do Paraná é composta por três unidades geomorfológicas principais, consistentes na Serra do Mar, no Primeiro Planalto e na Planície Costeira (ANGULO, 2004, p. 25).

Para Landucci e Ludwig (2005), as características geográficas do litoral paranaense identificam uma formação pré-cambriana (Serra do Mar) e uma ampla planície costeira - recortada pelas baías das Laranjeiras, de Antonina, de Paranaguá e de Guaratuba - que se estende desde o Canal do Varadouro, nas proximidades da Vila de Ararapira, Município de Guaraqueçaba, ao norte, limite com o Estado de São Paulo, até o Rio Saí-Guaçu, Município de Guaratuba, no limite sul com o Estado de Santa Catarina.

Concentra o local estudado uma área total de 5.630,8 $\mathrm{km}^{2}$ e uma população aproximada de 283.028 habitantes (238.134 habitantes na área urbana e 44.894 na zona rural), o que equivale a cerca de 2,79\% da população do Estado do Paraná (SUDERHSA, 2009).

\footnotetext{
${ }^{1}$ Guaraqueçaba, Antonina, Morretes, Paranaguá, Pontal do Paraná, Matinhos e Guaratuba.

${ }^{2}$ Definida pela Lei Estadual n. ${ }^{\circ}$ 13164/2001, como “o espaço geográfico delimitado pelos Municípios de: Guaraqueçaba, Antonina, Morretes, Paranaguá, Pontal do Paraná, Matinhos e Guaratuba. Compreendendo a Planície de Inundação Flúvio-marinha, constantes dos ecossistemas de manguezais e várzeas, da faixa marítima, até as doze milhas náuticas da costa, incluindo as ilhas costeiras e os hábitats rochosos, compondo um mosaico de ecossistemas de alta relevância ambiental, de diversidade marcada pela transição de ambientes terrestres e marinhos, com interações que lhe conferem o caráter de fragilidade" (art. 1. ${ }^{\circ}$, inciso I).
} 
Dentre seus principais rios encontram-se o Guaraqueçaba, do Salto, Tagaçaba, Serra Negra, São Sebastião, Cachoeira, Cacatu, Ipiranga, Marumbi, Cotia, Arraial, Matinhos, São João, Cubatão, Canavieiras, Saí-Guaçu, Cambará, da Onça, Cabaraquara, do Engenho, Nhundiaquara, Iporanga, Sagrado, do Meio, Mãe Catira e do Nunes (SEMA-PR, 2005, p. 9-14).

A bacia litorânea do Paraná pode ser subdividida em 6 sub-bacias, a saber: Ribeira, Baía das Laranjeiras, Baía de Antonina, Nhundiaquara, Baía de Paranaguá e Baía de Guaratuba, sendo que a do Ribeira é a única que não tem sua rede de drenagem direcionada às bacias de Paranaguá ou Guaratuba (DENES, 2006, p. 42).

Com relação aos volumes de demanda e disponibilidade, o balanço hídrico da bacia litorânea, segundo informações da SUDERHSA (2009), é bastante positivo, na medida em que há uma demanda de $1.212 \mathrm{l} / \mathrm{s}$, enquanto a disponibilidade é de 108.705 1/s, existindo um saldo positivo na ordem dos 107.918 1/s.

Mesmo diante da abundante disponibilidade quantitativa, a bacia litorânea do Paraná, em suas porções centro e norte, tem incidência de leptospirose acima da média, além da identificação, na região central da bacia, de casos de esquistossomose. Além disso, a quase totalidade de sua extensão encontra-se em área de risco de incidência de malária, fatos que somados apontam para a fragilidade da prestação de serviços de saneamento ambiental na região (SUDERHSA, 2009) e, consequentemente, para a contaminação dos seus corpos hídricos e crescente perda de disponibilidade.

Com relação ao saneamento básico, constata-se que $84,10 \%$ das residências urbanas do litoral paranaense não contam com serviço de coleta de esgoto (SUDERHSA, 2009). Esta informação justifica em grande parte a degradação da qualidade dos corpos hídricos da bacia litorânea do Paraná, assim como da balneabilidade de suas praias, com resultados não apreciáveis para a economia regional, que tem seu turismo, pesca e outras atividades econômicas bastante prejudicadas, sem falar nos sérios problemas de saúde pública decorrentes desta situação.

A partir do quadro evidenciado para esta localidade em relação aos serviços de saneamento, pode-se traçar uma projeção da política sanitária em âmbito nacional, adotando-se as devidas cautelas.

\section{Política Nacional de Saneamento sob o foco da Lei . $^{\circ} 5.318 / 1967$}

Antes da inserção direta no corpo da norma que regia a política sanitária no Brasil, necessária se faz a contextualização da edição e publicação da Lei n. ${ }^{0}$ 5.318/1967.

Como sabido, o ano de 1967 marca a história brasileira como um momento de forte opressão, expressado pelo regime de ditadura militar implantado no país com o golpe de 1964, tratando-se de um período de supressão e desrespeito às mais elementares garantias dos cidadãos (FICO, 2004).

Este período da história brasileira reflete um fragilizado equilíbrio entre a relação "liberdade x segurança", marcando o momento histórico de menor liberalidade concedida aos cidadãos, em troca de uma projeção de maior segurança.

No modelo anterior à Lei n. ${ }^{\circ} 5.318 / 67$, a gestão sanitária era relegada exclusivamente à iniciativa privada, especialmente ao capital internacional, único interessado em aportar investimentos no setor. Forte era a influência de Locke (2006) nesse mecanismo (individualismo burguês), que reconhecia a apropriação privada dos bens ambientais, assim como o seu gerenciamento.

Neste ponto se vê uma mudança da influência central norteadora da política pública de saneamento (e do Estado brasileiro, de modo geral), que passou a ter um caráter explicitamente hobbesiano, primando pela forte intervenção estatal por julgar os particulares, neste ponto, incapazes de atender aos anseios da coletividade e aos interesses da "segurança nacional”. De acordo com a concepção de Hobbes (2001), deve existir um poder visível capaz de manter os homens respeitosos, pressionando-os, pela imposição de sanções, ao cumprimento de suas tratativas e respeito às normas ${ }^{3}$.

Dentro deste espectro de visão, a política pública de saneamento representa um ponto estratégico para a manutenção da "paz e segurança" no seio das relações humanas, já que, nas sociedades onde haja prejuízos em sua disponibilidade, a potencialidade conflitiva tem margem para despontar.

A Política Nacional de Saneamento apresenta-se, dentro desta conjuntura, como mais uma rede de segurança que

\footnotetext{
${ }^{3}$ Numa visão contemporânea, Bauman (2003) traz novamente à tona a discussão acerca deste tema (liberdade x segurança) rebuscando o conceito de “comunidade", concebida como ente fechado e quase imaginário, representativo de um ideal de segurança (quase desprovido de liberdade), não perpassado pelas mazelas da sociedade.
} 
submete o agir humano em uma esfera pública de atuação bastante restrita (CASTEL, 2005).

Nos moldes da legislação citada, extrai-se que a Política Nacional de Saneamento emanada no ano de 1967 possuía vinculação com a Política Nacional de Saúde, o que é trazido de forma explícita logo no art. $1 .^{\circ}$ da Lei n. ${ }^{\circ}$ 5.318/1967.

O foco de abrangência do mencionado diploma legal, na forma do seu artigo $2 .^{\circ}$, dirigia-se ao saneamento básico - compreendendo abastecimento de água, fluoretação e destinação de dejetos; esgotos pluviais e drenagem; controle da poluição ambiental, inclusive do lixo; controle das modificações artificiais das massas de água e controle de inundações e de erosões.

Pode-se verificar de modo direto e objetivo também que a Lei n. ${ }^{\circ}$ 5.318/67 procedeu à transferência da atribuição de executar as atividades de saneamento ao Ministério do Interior. Dentro deste assentamento institucional, coube à Fundação SESP (Serviço Especial de Saúde Pública), junto com o Departamento Nacional de Obras e Saneamento (DNOS) e o Departamento Nacional de Endemias Rurais (DENERu), a execução da política sanitária formulada pelo Estado brasileiro (Fundo Fundação Serviços de Saúde Pública, 2008).

Por força de um acordo entabulado entre os Ministérios do Interior e da Saúde, em 1973, a Fundação SESP ficou praticamente destituída de sua ação executiva (restando extinta na década de 1990) e a administração dos sistemas de abastecimento de água e esgoto para os municípios foi transferida às empresas estaduais de saneamento. Especificamente no caso da bacia litorânea do Paraná, a Companhia de Saneamento do Paraná (SANEPAR), criada já em 1963 para o exercício destas atividades, ficou incumbida de tal competência, posteriormente partilhada com a Concessionária Águas de Paranaguá S.A., Companhia de Água e Esgoto de Paranaguá (CAGEPAR) e Serviço Municipal de Água e Esgoto de Antonina (SAMAE).

Admite-se de modo geral que, entre outras finalidades, o Plano Nacional de Saneamento - PLANASA, nos moldes instituídos pela Lei . $^{\circ} 5.318 / 67$, visava regulamentar a destinação e aplicação de recursos advindos do Fundo de Garantia por Tempo de Serviços (FGTS) para investimento no setor de saneamento (SANTOS, 2005).
A crescente arrecadação do FGTS, a busca pela consolidação de uma política nacional de saneamento e o aumento descontrolado da demanda levou o governo federal a implementar, em 1968, o Sistema Financeiro do Saneamento (SFS), que inicialmente tinha apenas disponíveis os recursos do Banco Nacional da Habitação (LUCENA, 2006, p. 7).

Contudo, a partir de 1969, o BNH (por meio do Decreto-Lei n. ${ }^{\circ}$ 949/69) foi autorizado a aplicar as verbas do FGTS nas operações de financiamento para saneamento, o que permitiu a criação de vários novos programas de custeio destes empreendimentos (SANTOS, 2005; SANTOS; PAULA, 1989).

Já naquela época, entendem alguns pesquisadores (SANTOS, 2005) que o sistema foi fundado na filosofia da viabilização e acesso global, baseado na economia de escala e apoiado na concentração dos serviços de saneamento em empresas estaduais, com atuação no foco regional, em detrimento da gestão municipal.

Para gerenciar as demandas atinentes ao saneamento básico, foi criado pela Lei n. ${ }^{\circ}$ 5.318/67 o Conselho Nacional de Saneamento (CONSANE), órgão colegiado, que possuía a missão institucional de exercer as atividades de planejamento, coordenação e controle da Política de Saneamento.

Ocorre que o CONSANE nunca teve funcionamento capaz de suprir as expectativas criadas a seu redor, mantendo-se elevado o déficit de prestação de serviços de saneamento, o que deu ensejo, em 1970, ao lançamento do PLANASA pelo então Presidente Médici (LUCENA, 2006, p. 5), que possuía a ambiciosa pretensão de estender - até o início da década de 1980 - a $80 \%$ da população brasileira o serviço de distribuição de água tratada e a $50 \%$ das residências brasileiras o serviço de coleta e tratamento de esgoto.

Não obstante a existência de vozes em sentido contrário (COSTA, 2003, p. 26) ${ }^{4}$, o discurso do Plano Nacional de Saneamento primava por um modelo descentralizado de gestão sanitária, através da participação de organismos dos Estados, municípios e até mesmo do setor privado, o que representou uma atitude que pode ser considerada como vanguardista, pois advinha de um regime militar ditatorial.

No contexto de aplicação do PLANASA, foram definidos papéis e funções institucionais específicos, a saber (LUCENA, 2006, p. 7):

\footnotetext{
${ }^{4}$ Defende o mencionado autor, com bastante razão, que o PLANASA foi concebido em forma de uma política nacional, dentro de uma visão centralizadora, de cunho vertical.
} 
[...] o BNH era incumbido de gerir o sistema, aprovar as propostas de investimentos estaduais, averiguar a viabilidade técnica dos programas e fiscalizar as companhias estaduais de saneamento Básico (CESBs), os governos estaduais teriam o controle acionário das CESBs e o setor privado participaria, por meio das empreiteiras e das indústrias de materiais e equipamentos (ALIANÇA PESQUISA E DESENVOLVIMENTO, 1995).

Porém, a mera definição de papéis não foi suficiente para a implementação do PLANASA, na medida em que o Brasil atravessou uma aguda crise econômica entre o final da década de 1970 e o início da década de 1980, fato que ensejou a insuficiência da principal fonte financiadora dos investimentos em saneamento (o Fundo de Garantia por Tempo de Serviço - FGTS), em razão dos saques realizados pelos titulares das verbas e da pequena taxa de geração de novos empregos e, via de consequência, de novos contribuintes para o Fundo de Garantia por Tempo de Serviço (MELO, 1989).

Ademais, muitas municipalidades deixaram de aderir ao PLANASA e tampouco efetivaram a concessão dos serviços às companhias estaduais de saneamento, o que impediu que os sistemas mais lucrativos financiassem os menos viáveis economicamente (LUCENA, 2006. p. 8).

Outra distorção enfrentada pelo PLANASA diz respeito ao fato de que as tarifas realistas não puderam ser praticadas, pois percebeu-se que grande parte da população atendida não possuía disponibilidade financeira para arcar com um preço que internalizasse todas as externalidades ${ }^{5}$ que envolvem a questão. Era inviável, naquela oportunidade, introjetar mecanismos capazes de corrigir as distorções entre o preço de mercado cobrado pelos serviços de saneamento e o seu real custo social e ambiental.

Considerados casos clássicos de bens públicos, os serviços de saneamento não são objeto de transação em um mercado plenamente definido em termos de preços e quantidades (CARRERA-FERNANDEZ; GARRIDO, 2003, p. 66), o que leva à existência de uma variação muito significativa entre os serviços que os consumidores desejariam obter e o preço que estariam dispostos a pagar, o que tem influência direta na formação de preços e no tipo de serviço oferecido.

Frente à crise de implementação do PLANASA, o poder público promoveu o lançamento, em 1982, do Programa de Abastecimento de Água e Saneamento para População de Baixa Renda da Zona Urbana (PROSANEAR), visando atender às populações urbanas de baixa renda, classe mais vulnerável diante dos serviços de coleta e tratamento de esgotos prestados no mercado nacional até o momento.

Inicialmente, o financiamento deste programa ficou a cargo da União, passando, no final da década de 1980 (já durante o processo de transição democrática do Estado brasileiro), para as mãos do Banco Mundial, Estados, Municípios e Caixa Econômica Federal, quando recebeu a denominação de PROSANEAR I (BANCO MUNDIAL, 1990).

Pode-se afirmar que, com o PROSANEAR I, conjugaram-se pela primeira vez no Brasil as definições de saneamento, saúde e meio ambiente (LUCENA, 2006, p. 9), a fim de se promover a melhoria da qualidade de vida da faixa mais carente da população. E o que é ainda mais relevante: pela primeira vez, prestigiou-se a participação popular na formulação da política pública de saneamento, o que reflete um embrião de gestão democrática e participativa na prestação destes serviços.

A participação comunitária neste caso, no entanto, representava mera colaboração dos populares para viabilizar a passagem de instalações por suas propriedades e integração entre vizinhanças, a fim de gerar condições de uso em escala para a tecnologia mais barata na ocasião, consistente no sistema condominial de coleta de esgotos - ligação a um grupo de domicílios como se um edifício horizontal fosse (SANTOS; PAULA, 1989).

Mesmo com a boa estruturação, o PROSANEAR I também sofreu aguda crise decorrente das dificuldades financeiras enfrentadas pelas companhias estaduais de saneamento e do número crescente de domicílios não atendidos pela rede de coleta e tratamento, notadamente aqueles localizados em

\footnotetext{
${ }^{5}$ O conceito econômico de "externalidades" pode ser definido como "efeitos externos tecnológicos no consumo ou na produção [...]" (CARRERA-FERNANDEZ; GARRIDO, 2003, p. 66). Nas palavras de Acselrad (1994, p. 131) "A intensidade e extensão em que é feita a exploração econômica dos recursos naturais pode comprometer o equilíbrio dos ecossistemas, alterando regimes hidrológicos e climáticos, empobrecendo solos, diminuindo a capacidade de absorção de $\mathrm{CO}_{2}$ por maciços florestais etc." Estes efeitos narrados acima compreendem, de fato, aquilo a que a teoria econômica chamou de externalidade, que compreende "danos causados por alguma atividade a terceiros, sem que esses danos sejam incorporados no sistema de preços" (ACSELRAD, 1994, p. 132). Ao dizer que os preços não computam o dano causado por empreendimentos privados sobre bens coletivos, pode-se afirmar que tais atividades geram custos sociais superiores aos seus custos privados de apropriação da natureza e exploração de determinada atividade econômica. Isto quer dizer que os resultados de certos esforços de investimento são apropriados gratuitamente ou sofridos involuntariamente por terceiros (ACSELRAD, 1994, p. 132).
} 
áreas loteadas de forma irregular e sensíveis do ponto de vista ambiental. Ademais, a falta de sustentabilidade econômica foi a tônica dos programas de saneamento do governo brasileiro (LUCENA, 2006, p. 12), o que se repetiu nos anos de 1986 a 1989, com o Programa Nacional de Desenvolvimento da Nova República, editado já no governo Sarney (em plena transição democrática) e com o Programa de Ação Governamental, no período de 1987 a 1991.

\section{A “nova” Política Nacional de Saneamento}

Representa a década de 1980 um marco na história do Brasil (e do mundo), pois foi representativa da introdução de uma série de novas visões de mundo em diversos campos da vida.

A abertura política dos países da América Latina em geral, passando de um regime de totalitarismo militar para uma democracia formal, foi um dos destaques deste período, aliado a vários outros processos que culminaram com a queda do bloco socialista e com a consolidação dos "tigres asiáticos", por exemplo.

No Brasil, os reflexos dessas reviravoltas desencadearam um processo de democratização das relações entre Estado e sociedade civil, com crescente abertura dos espaços de interlocução em uma esfera pública cada vez mais plural (DAGNINO, 2004, p. 95). O resultado mais evidente desta abertura democrática é a Constituição Federal de 1988, denominada "Constituição Cidadã".

No corpo do texto constitucional, consta, em seu artigo 21, XX, que compete à União "instituir diretrizes para o desenvolvimento urbano, inclusive habitação, saneamento básico e transportes urbanos". Desta feita, verifica-se que a União tem competência para estabelecer diretrizes gerais sobre as ações voltadas à implementação do saneamento, cabendo aos Estados, Distrito Federal e Municípios, na forma do art. 23, IX, proceder a ações sanitárias materiais nos âmbitos regional e local, de acordo com suas peculiaridades.

Não foi cristalina o suficiente a Constituição da República para determinar qual o ente governamental, se Estado ou Município, detém a titularidade para conferir, em regime de concessão, o direito para a exploração dos serviços de saneamento no território brasileiro. Maior incerteza paira sobre as áreas metropolitanas, em municípios limítrofes, que compartilham a mesma fonte hídrica. De toda forma, os Estados já demonstraram interesse em avocar para si a concessão do direito de exploração sobre essas áreas (PETERSEN; BRANCHER, 2000).
Nesta medida, a normatização no âmbito federal está restrita à fixação de orientações básicas, que devem ser observadas pelos demais entes federados, na ação reguladora da atividade de sua competência, assim como na fixação de critérios de prioridade com vistas à universalização mais eficiente do acesso aos serviços de água tratada e esgotamento sanitário (PETERSEN; BRANCHER, 2000).

Entretanto, a dinâmica de construção da democracia no Brasil enfrenta um problema cuja gênese se encontra na perversa confluência entre dois processos distintos. Por um lado, veem-se os frutos da abertura democrática, acima mencionada de forma sucinta. De outro, a pressão internacional pelos ajustes neoliberais que demandam a redução do Estado a um patamar mínimo, o qual, sob esta ótica, deve relegar à sociedade civil a garantia dos direitos sociais, nos moldes entabulados no Consenso de Washington, em 1989.

Entre o seio do amadurecimento e da consolidação destes dois projetos aparentemente antagônicos (DAGNINO, 2004, p. 96), restou promulgada a Lei n. ${ }^{\circ} 11.445 / 2007$, responsável pela positivação da nova Política Nacional de Saneamento, estabelecendo "diretrizes nacionais para o saneamento básico" (Lei n. ${ }^{\circ} 11.445 / 2007$, preâmbulo).

Com relação à lei anterior, o objeto da Lei n. ${ }^{\circ}$ $11.445 / 2007$ possui pequenas modificações - algumas delas condizentes apenas à nomenclatura de certas atividades -, as quais dão maior precisão técnica aos dispositivos. Apesar do objeto da norma conter poucas alterações, a perspectiva com que o assunto é tratado sofreu mudanças radicais.

As diretrizes da nova política sanitária são representadas pelos princípios da universalidade do acesso; integralidade da prestação; proteção à saúde e ao meio ambiente; respeito às particularidades locais e regionais; articulação com políticas de desenvolvimento urbano e regional, de habitação, de combate à pobreza, de proteção ambiental, de saúde e outras de relevante interesse social; sustentabilidade econômica; progressividade das soluções, considerando a capacidade de pagamento dos usuários; transparência; controle social; segurança e integração com a gestão de recursos hídricos.

Como se vê, a complexidade da nova política sanitária é maior do que a trazida no regramento de 1967 , na medida em que este previa somente a articulação com a política de saúde, enquanto que aquela estende esta integração a outras políticas de relevante interesse social. A visão de mundo que baseou a edição da Lei n. ${ }^{\circ} 11.445 / 2007$ entendeu, de certo modo, a necessidade de compreensão holística da questão sanitária (BERTALANFFY, 1977; CAPRA, 1996; 
MORIN, 2000), considerando as demandas emergentes em uma realidade multifacetada e não linear.

Corroborando esta afirmativa, cita-se o entendimento do professor Heller $(2005$, p. 2), para o qual "autores vêm reconhecendo que desenhar um futuro mais justo para o atendimento à população pelos serviços impõe combinar vários fatores, em uma abordagem mais sistêmica". Neste diapasão, pode-se concluir que a atual Política Nacional de Saneamento advém de um processo de descentralização, integração e flexibilização da política federal sobre o tema (ARRETCHE, 1999, p. 86).

É de se suscitar que a atual lei sanitária determina aos titulares dos serviços que formulem a respectiva política pública de saneamento básico, devendo, para tanto estabelecer mecanismos de controle social (art. 9. $\left.{ }^{\circ}, \mathrm{V}\right)$, o que reflete, ao menos formalmente, um espírito de acolhida da participação da sociedade civil na gestão da política de saneamento. Isto se repete em outros momentos, como no art. 11 , IV e $\S 2 .^{\circ}$, V, da Lei n. ${ }^{\circ} 11.445 / 2007$ - o qual prevê, como condição de validade do contrato firmado entre a administração pública e o prestador de serviços de saneamento, a realização prévia de audiência e consulta públicas sobre o edital de licitação e a minuta do contrato, bem como a presença de mecanismos de controle social em caso de contratos de concessão de serviço público de saneamento.

Ademais, o $\S 3 .^{\circ}$ do mesmo artigo prevê que "os contratos não poderão conter cláusulas que prejudiquem as atividades de regulação e de fiscalização ou o acesso às informações sobre os serviços contratados".

Outras expressões de valorização da participação social na política de saneamento encontram-se na necessidade de realização de consulta ou audiência pública sobre os planos de implementação e os estudos que lhe dão suporte (art. 19, §5. ${ }^{\circ}$, complementado pelos artigos 26, 27 e 51).

Diga-se ainda que a Lei n. ${ }^{\circ} 11.445 / 2007$ destinou um capítulo inteiro à participação de órgãos colegiados de caráter consultivo no controle social da política de saneamento, nos quais é assegurada a participação dos usuários dos serviços de saneamento e da sociedade civil organizada.

Este viés democrático, por razões óbvias, não era admitido no regime legal anterior, sob pena de dar vazão a "atitudes subversivas" que seriam contrárias à "segurança nacional", defendida de maneira robusta pelo regime militar ditatorial brasileiro.
Não obstante o espírito democrático da Lei n. ${ }^{\circ}$ $11.445 / 2007$, vozes de relevo defendem que a participação popular é mero instrumento retórico da norma, pouco consolidada e bastante rejeitada pelo aparato governamental (HELLER, 2005). Aqui se verifica uma possibilidade de aproximação das discussões entre a política de saneamento e de recursos hídricos, onde vozes defensoras de um pensamento contra-hegemônico sustentam a exclusão da participação social sob o argumento do tecnicismo e da "cidadania responsável", de acordo com os quais a participação na gestão do saneamento (e das águas) estaria restrita àqueles que detêm os conhecimentos técnicos necessários ao debate (CAUBET, 2004, p. 107).

Por outro lado, o setor de saneamento passou a ser objeto de interesse de empresas nacionais e multinacionais, que dirigiram esforços para integrar este expressivo mercado (SANCHEZ, 2001).

A opção pela gestão privada dos sistemas de saneamento parecia um trilho sem volta, integradora de um amplo processo de reforma neoliberal do Estado em que temas como a desestatização, a modernização do setor público e a desregulamentação passaram a ser tratados quotidianamente. Nesse espectro, não havia muitos motivos para se acreditar que o setor de saneamento seria conduzido a um caminho diverso ao de outros setores de infraestrutura gerenciados pelo Estado, os quais em pouco tempo passaram para as mãos da iniciativa privada por meio do Programa Nacional de Desestatização.

Ocorre que, no Brasil, a onda de privatização dos serviços de saneamento, em um primeiro momento, não foi bem sucedida, haja vista a forte resistência social (como no caso do Paraná, onde a pressão para a não privatização da SANEPAR foi significativa) e a antieconomicidade gerada pela possível existência de mais de uma prestadora de serviços na mesma região - que afastou boa parte dos interessados (SANCHEZ, 2001).

Ora, os serviços de saneamento constituem verdadeiro monopólio natural ${ }^{6}$, exigindo atuação em escala (quanto maior a produção/prestação, menor o seu custo) para viabilizar economicamente a manutenção dos empreendimentos e a prestação de serviços (CARRERA-FERNANDEZ; GARRIDO, 2003; SANCHEZ, 2001).

\footnotetext{
${ }^{6}$ Nas palavras de Possas et al. (1998, p. 3), “tipo de estrutura de mercado suscetível de justificar teoricamente a regulação pública, na expectativa de que os ganhos de custos unitários associados à instalação e à operação de uma única unidade (planta ou empresa) mais que compensem os custos e riscos de ineficiência de sua regulação".
} 
Importante ainda trazer à colação que, ao se buscar auferir o grau evolutivo do setor de saneamento nos países em desenvolvimento, pode-se identificar uma marca comum consistente na matriz conceitual e tecnológica preponderante (HELLER, 2005, p. 1). Um panorama histórico relativo à implantação das iniciativas na área de saneamento indica um forte estigma da importação de tecnologias da Europa e da América do Norte, muito pouco filtradas pela realidade local. Essa matriz hegemônica ainda hoje prepondera e pouco se tem efetivado no sentido da implementação de visões de saneamento genuinamente locais, regionais ou nacionais.

Este fato tem consequências que merecem um estudo mais aprofundado (que não é objeto deste trabalho), pois os países e regiões possuem diferentes necessidades e soluções no campo sanitário. Se a agenda tecnológica dos países do norte observa assuntos ligados a realidades que já superaram o problema da universalização da cobertura pelos serviços de saneamento, a dos países periféricos precisa dirigir o foco para a dívida social acumulada nesta seara (HELLER, 2005, p. 1). O enfrentamento destes problemas, como identificado em parte pela atuação governamental no Brasil, demanda um olhar interdisciplinar e atuação intersetorial, a partir de um emergente paradigma de atuação complexa ainda em construção.

Além da importação de modelos sem a devida atenção para as peculiaridades locais, regionais e nacionais, o Programa das Nações Unidas para os Assentamentos Humanos (UN-Habitat, 2003) reconhece que dois tipos de dificuldades institucionais têm servido como obstáculo para a expansão do acesso aos serviços de saneamento, a saber: ausência de instituições apropriadas em todas as esferas de governo e disfunção crônica das estruturas institucionais existentes (LENTON et al., 2005).

Pode-se vislumbrar, no Brasil e em alguns outros países, um esforço para resgatar a função original dos serviços sanitários enquanto elemento de prevenção e promoção da saúde humana, o que gera importantes consequências conceituais, tecnológicas e políticas (HELLER, 2005, p. 3).

Em linhas gerais, estas são as principais características da atual Política Nacional de Saneamento, o que nos revela a magnitude dos desafios a serem enfrentados.

\section{Dados sobre a efetivação da política sanitarista}

Serão apresentados nesta oportunidade dados acerca da cobertura pelo sistema de saneamento no Brasil, no
Estado do Paraná e na bacia litorânea do Paraná, especialmente no que diz respeito ao atendimento da população pelo serviço de esgotamento sanitário. Os dados indicados serão analisados no tópico seguinte, onde se expressa uma conclusão acerca do tema objeto de investigação.

Em âmbito nacional, as informações são preocupantes. De acordo com a pesquisa denominada "Impactos Sociais de Investimentos em Saneamento", da Fundação Getúlio Vargas (FGV, 2007), a falta de saneamento básico (entenda-se falta de serviço de coleta de esgoto) assola $47 \%$ da população brasileira, sendo as crianças de 1 a 6 anos as vítimas mais vulneráveis. A pesquisa ressalta que, no ritmo atual, apenas em 2122 o Brasil deve ter acesso total ao esgotamento sanitário, haja vista a lentidão no desenvolvimento da universalização do serviço de captação de esgotos e a restrição das alternativas para a prestação desta atividade (PGR, 2008).

Os dados estatísticos do IBGE (Pesquisa Nacional de Saneamento Básico, 2000) demonstram que, dos 9.848 distritos que integram os municípios da Federação brasileira, 5.571 não têm rede coletora de esgoto, o que representa um total de $56,56 \%$. Mais de $90 \%$ dos domicílios não servidos pela rede coletora utilizam-se do sistema de fossa séptica ou fossa seca para a disposição final de seu esgoto. $\mathrm{O}$ restante utiliza-se de destinação em valas abertas ou lançamento em cursos d'água, sem qualquer tipo de tratamento. Apenas uma ínfima parcela utiliza-se de soluções alternativas.

Ainda de acordo com os elementos apontados pela Pesquisa Nacional de Saneamento Básico do IBGE, dos 4.097 distritos onde há sistema de coleta de esgotos, apenas $33,76 \%$ dos mesmos dá tratamento aos dejetos captados, sendo que os outros $66,24 \%$ despejam os efluentes no ambiente (especialmente em corpos hídricos), sem qualquer tipo de tratamento. Verifica-se assim que, mesmo quando o esgoto é coletado, na grande maioria dos casos, não é tratado, sendo despejado diretamente na natureza.

Com relação ao Estado do Paraná, levantamento efetuado pela extinta Superintendência de Desenvolvimento de Recursos Hídricos e Saneamento Ambiental (SUDERHSA) remonta que $76,5 \%$ da população urbana no Estado não é prestigiada com redes de coleta de esgoto.

Estes dados indicam que a situação do Paraná está muito abaixo da média nacional de atendimento com redes de coleta de esgoto, fato que coloca em xeque o mito de que a sociedade paranaense se encontra em avançado estágio de desenvolvimento se comparada a outras regiões do país. 
Na bacia litorânea do Paraná, as informações são ainda mais comprometedoras. Como se constata do estudo supracitado realizado pela extinta SUDERHSA, apenas $15,9 \%$ da população urbana da região costeira do Estado é servida com redes de coleta de esgotamento sanitário. Com relação ao tratamento destes rejeitos coletados, a situação é ainda mais precária.

Apresentados e analisados superficialmente os elementos concretos atinentes aos serviços de esgotamento sanitário em focos nacional, regional e local, passa-se às conclusões extraídas dos elementos teóricos e ontológicos colhidos.

\section{Considerações finais}

A partir dos dados colacionados, pode-se afirmar que a sociedade brasileira se encontra diante de um problema recorrente: a efetivação dos direitos, em especial daqueles que são reconhecidos como fundamentais para a vida e a digna existência dos indivíduos e da sociedade como um todo.

Os índices de universalização dos serviços sanitários, demonstrados por elementos concretos e objetivos, indicam caminho inquestionável para o abismo existente entre a boa técnica legislativa aplicada na Lei n. ${ }^{\circ} 11.445 / 2007$ e a realidade vivida pelo cidadão brasileiro.

O Estado de Direito é grande demarcador dos direitos fundamentais individuais e coletivos; contudo, enfrenta uma crise quando se trata da materialização do conteúdo de suas regras jurídicas, sobremaneira daquelas que demandam prestações do Estado em face dos cidadãos. Este é o caso dos direitos fundamentais à vida, à saúde, à dignidade e a um meio ambiente ecologicamente equilibrado para as presentes e futuras gerações, os quais incontestavelmente possuem pontos de toque com a Política Nacional de Saneamento.

Trata-se de uma fragilidade há muito identificada pelos pesquisadores e estudiosos, tratada em obra clássica de Bobbio (2004), na qual o "jusfilósofo" apresenta o ponto nevrálgico da questão: não importa o fundamento dos direitos fundamentais e sim sua efetivação nas relações sociais concretas. E o que se vê no caso é que, mesmo com a constitucionalização da questão sanitária, a crise de materialização deste direito persiste.

A eficácia jurídica dos direitos não corresponde à sua eficácia social, que diz respeito à materialização do conteúdo normativo no plano da vivência quotidiana (BARROSO, 1998). A efetividade dos direitos, sob esta visão de mundo, corresponde ao desempenho concreto da função social do direito, ou seja, à utilização do Direito como instrumento de luta para atendimento das necessidades sociais.

Além do problema de efetivação, mister investigar de modo atento a preconizada participação social na política sanitária, que induz à primeira vista a conclusão de que a gestão desta atividade é procedida de forma democrática.

Neste sentido, pode-se afirmar que a participação democrática e plural só pode ser considerada quando efetivamente os agentes conseguem se fazer representar no resultado das deliberações coletivas, mesmo que configurem minorias, situação que não é prestigiada em sua plenitude no atual sistema de gerenciamento de recursos hídricos (CAUBET, 2004).

Dentro da relação de forças incutida nas relações que permeiam a política de saneamento, aqueles que se encontram nas posições hierárquicas de dominação tendem a utilizar estratégias dirigidas à manutenção da ordem estabelecida, em oposição àqueles que estão em condição de inferioridade, que se dirigem ao comodismo ou à ação subversiva, amparada por limites que não comprometam a existência do próprio microcosmo (revoluções parciais), sob pena de autoexclusão.

O pensamento hegemônico (exteriorizado neste caso para a Política Nacional de Recursos Hídricos, mas com aplicação à gestão sanitária) - manifestado aqui, de forma exemplificada, pelo Secretário de Meio Ambiente do Estado do Paraná (PARANÁ, 2008) - é conduzido no sentido de se afirmar que "O Paraná tem uma política acertada e também conhecida no Brasil pela consolidação dos Comitês de Bacias, em processo descentralizado e participativo. Ou seja, a transferência da responsabilidade, hoje apenas do Estado, em cumplicidade com usuários e setores organizados".

Em outro viés, autores de grande envergadura têm compreensão distinta, afirmando que, na prática, a participação e descentralização nas políticas públicas são meros instrumentos retóricos da legislação que não se consolidam no plano de aplicação e execução das normas. Exemplo deste posicionamento é aquele defendido por Caubet (2004), no sentido de que, apesar da Lei de Recursos Hídricos falar em descentralização da gestão do bem ambiental água, de acordo com o rigor científico, refere-se à mera desconcentração (delegação), pois não dá condições de influenciar as decisões àqueles que anteriormente não possuíam tal poder, pensamento que se amolda de forma integral também à política de saneamento. A lei apenas transfere a outros entes administrativos, através de delegação - com intenção de desabarrotar seus gabinetes - a competência e a autoridade para realizar determinados atos (BRANNSTROM, 2002). 
O pensamento reproduzido pelos detentores de posições-chave na teia de relacionamentos pertinente à gestão do saneamento tende a manter a situação vigente, ou, no mínimo, inviabilizar o avanço de dinâmicas que possam alterar o estado das coisas. Mesmo diante da instauração de uma nova conjuntura, onde foram inseridos atores, cenários e interesses, continuaram os defensores dos velhos interesses (apropriação privada dos recursos naturais, reverberando uma posição capitalista, patrimonialista e utilitarista) a manter seu lugar de hegemonia, haja vista as relações clientelistas que entabularam no curso da história com os detentores do poder político. Trata-se de grave contrassenso advindo da tradição política e cívica brasileira, já que o particularismo das relações pessoais (VAITSMAN, 2002) se faz enraizado na formação e composição dos órgãos responsáveis pelo gerenciamento da política de saneamento, o que representa um fator de exclusão e desigualdade. Os grandes responsáveis pela gestão sanitária - especialmente empresas de saneamento, muitas destas com participação acionária de conglomerados internacionais atuando em empreendimentos custeados pelo poder público - possuem fortes e antigos laços que atravessam os novos arranjos institucionais, fazendo com que permaneçam em posição de hegemonia, em detrimento de toda a coletividade.

\section{Referências}

ACSELRAD, H. Externalidade Ambiental e Sociabilidade Capitalista. In: CAVALCANTI, C. (Org.). Desenvolvimento e natureza: Estudos para uma sociedade sustentável. Recife: INPSO/FUNDAJ, Instituto de Pesquisas Sociais, Fundação Joaquim Nabuco, Ministério da Educação, Governo Federal, 1994. Disponível em: <http://168.96.200.17/ar/libros/brasil/ pesqui/cavalcanti.rtf $>$. Acesso em: 22.06.2009.

ANGULO, R. J. Mapa do Cenozóico do Litoral do Estado do Paraná. Boletim Paranaense de Geociências, n. 55, p. 25-42, 2004.

ARRETCHE, M. T. S. Política Nacional de Saneamento: a reestruturação das companhias estaduais. Brasília: IPEA, 1999.

BANCO MUNDIAL. PROSANEAR: experiências inovadoras em saneamento para as populações de baixa renda no Brasil. Brasília: Banco Mundial, 1990.

BARROSO, L. R. O Direito Constitucional e a efetividade de suas normas: limites e possibilidades da Constituição Brasileira. Rio de Janeiro: Renovar, 1993. Rey, 1998.
Vê-se neste ponto um desvio do foco da busca da igualdade e plena cidadania no campo social, o que encoberta as raízes históricas da desigualdade na sociedade brasileira (COSTA, 2006). Meras regras de estruturação dos sistemas de tomada de decisão na gestão sanitária não podem ser confundidas com uma gestão democrática de fato, já que servem, na prática, apenas para afastar o cidadão comum das articulações travadas na esfera pública.

Através da negociação sociotécnica (MACHADO, 2005), os sujeitos envolvidos na política de saneamento, com base em critérios de sustentabilidade, deveriam orientar-se por um estilo de ação dirigido a superar o modelo tecnocrático, subjugado normalmente a interesses econômicos e políticos, o que não se tem verificado na prática.

Não se pode perder de vista que no pano de fundo desta situação vigoram interesses econômicos das empresas prestadoras dos serviços públicos de saneamento, que visam a todo custo defender a sua viabilidade financeira.

Mas o foco meramente no resultado capitalista tem forte probabilidade de relegar ao esquecimento outros fatores importantes para a integração das políticas públicas e sociais, como o prestígio da saúde pública e do meio ambiente, e recair na velha prática voltada para a privatização dos lucros e socialização dos prejuízos.

BAUMAN, Z. Comunidade: a busca por segurança no mundo atual. Rio de Janeiro: Jorge Zahar, 2003.

BERTALANFFY, L. V. Teoria Geral dos Sistemas. 3. ed. Tradução Francisco M. Guimarães. Petrópolis: Vozes.

BOBBIO, N. A era dos Direitos. 4. ed. Rio de Janeiro: Campus, 2004.

BRANNSTROM, C. Decentralizing water-resources management in Brazil. Bellagio: Conference on Decentralization and the environment, 2002.

BRASIL. Lei n. 5.318 de 26 de setembro de 1967. Institui a Política Nacional de Saneamento e cria o Conselho Nacional de Saneamento. Brasília, DF, 1967.

Constituição da República Federativa do Brasil de 05 de outubro de 1988. Brasília, DF, 1988.

Lei n. 11.445 de 05 de janeiro de 2007. Estabelece diretrizes nacionais para o saneamento básico; altera as Leis 
n. ${ }^{\circ}$ s 6.766 , de 19 de dezembro de $1979,8.036$, de 11 de maio de 1990, 8.666, de 21 de junho de 1993, 8.987, de 13 de fevereiro de 1995; revoga a Lei n. ${ }^{\circ} 6.528$, de 11 de maio de 1978; e dá outras providências. Brasília, DF, 2006.

CAPRA, F. A teia da vida: uma nova compreensão científica dos sistemas vivos. São Paulo: Cultrix, 1996.

CARRERA-FERNANDEZ, J.; GARRIDO, R. J. Economia dos recursos hídricos. Salvador: UFBA, 2003.

CASTEL, R. A insegurança social: o que é ser protegido? Petrópolis: Vozes, 2005.

CAUBET, C. G. A água, a lei, a política... E o meio ambiente? Curitiba: Juruá, 2004.

COSTA, A. M. Avaliação da Política Nacional de Saneamento, Brasil - 1996/2000. Tese (Doutorado) - Programa de Pós-Graduação da Escola Nacional de Saúde Pública. Fiocruz. 248 p. Rio de Janeiro, 2003.

COSTA, L. C. Os impasses do estado capitalista: uma análise sobre a reforma do Estado no Brasil. Ponta Grossa: UEPG, 2006.

DAGNINO, E. ¿Sociedade civil, participação e cidadania: de que estamos falando? In: MATO, D. (Coord.). Políticas de ciudadanía y sociedad civil en tiempos de globalización. Caracas: FACES, Universidad Central de Venezuela, p. 95-110, 2004.

DENES, F. Caracterização da pressão antrópica no Parque Nacional Saint-Hilaire/Lange (Litoral do Paraná). Dissertação (Mestrado) - Programa de Pós-Graduação em Geografia, Setor de Ciências da Terra, Universidade Federal do Paraná, 120 p. Curitiba, 2006.

FGV - FUNDAÇÃO GETÚLIO VARGAS. Impactos sociais de investimentos em saneamento. Centro de Políticas Sociais. São Paulo: FGV, 2007.

FICO, C. Versões e controvérsias sobre 1964 e a ditadura militar. Revista Brasileira de História, v. 24, n. 47, 2004.

FUNDO FUNDAÇÃO SERVIÇOS DE SAÚDE PÚBLICA. Disponível em: <http://www.coc.fiocruz.br/areas/dad/guia acervo/arq pessoal/fundo_sesp.htm>. Acesso em: 22.07.2008.

HELLER, L. Política pública e gestão dos serviços de saneamento a partir de uma visão de saúde pública. In: ENCUENTRO POR UMA NUEVA CULTURA DEL ÁGUA EM AMÉRICA LATINA. Fortaleza. Zaragoza: Fundacion Nueva Cultura del Agua, 2005. Anais... Disponível em: <http://www.unizar. es/fnca/america/docu/0802.pdf $>$. Acesso em: 21.07.2008.

HOBBES, T. Leviatã ou a matéria, forma e poder de um Estado eclesiástico e civil. São Paulo: Martin Claret, 2001.
IBGE. Pesquisa Nacional de Saneamento Básico. Brasília, 2000. Disponível em: <http://www.ibge.gov.br/home/estatistica/populacao/condicaodevida/pnsb/esgotamento sanitario/ esg_sanitario46.shtm $>$. Acesso em: 21.07.2008.

LANDUCCI, M.; LUDWIG, T. A. V. Diatomáceas de rios da bacia hidrográfica litorânea, PR, Brasil: Coscinodiscophyceae e Fragilariophyceae. Acta Bot. Bras. [online], v. 19, n. 2, p. 345-357, 2005. Disponível em: <http://www.scielo. br/scielo.php?pid=S0102-33062005000200018\&script $=$ sci arttext\&tlng $=\mathrm{pt}>$. Acesso em: 01.04.2009.

LENTON, R.; WRIGHT, A. M.; LEWIS, K. (Coord.). Health, dignity and development: what will it take? Achieving the Millennium Development Goals. Londres: Earthscan, Londres, 2005. 229 p. Disponível em: $<$ http://unmp.forumone.com/ eng_task_force/WaterEbook.pdf>. Acesso em: 18.07.2008.

LOCKE, J. Segundo tratado sobre o governo civil. 4. ed. Petrópolis: Vozes, 2006.

LUCENA, A. F. As políticas públicas de saneamento básico no Brasil: Reformas institucionais e investimentos governamentais. Revista Plurais (On-line), v. 1, p. 117-130, 2006.

MACHADO, J. S. Descrição e análise das relações entre gestão de água doce e exercício da cidadania no Brasil contemporâneo. In: MINAYO, M. C. S.; COIMBRA JUNIOR, C. E. A. (Org.). Críticas e atuantes: ciências sociais e humanas em saúde na América Latina. Rio de Janeiro: Fiocruz, 2005.

MELO, M. A. B. C. O padrão brasileiro de intervenção pública no saneamento básico. Revista Brasileira de Administração Pública, v. 23, n. 1, p. 84-102, 1989.

MORIN, E. O pensamento complexo, um pensamento que pensa. In: MORIN, E.; LE MOIGNE, J. L. A inteligência da complexidade. Tradução: Nurimar Maria Falci. São Paulo: Peirópolis, 2000.

PARANÁ. Instituto Ambiental do Paraná - IAP. Paraná realizará o mais importante encontro das Américas sobre águas, Curitiba. Disponível em: <http://www.sema.pr.gov. $\mathrm{br} /$ modules $/$ noticias $/$ article.php? storyid $=378>$. Acesso em: 17.05.2008.

PETERSEN, O.; BRANCHER, P. A privatização do setor de saneamento básico no Brasil. Jus Navigandi, 2000. Retirado de $<$ http://jus2.uol.com.br/Doutrina/texto.asp?id $=450>$. Acesso em: 21.07.2008.

PGR - PROCURADORIA-GERAL DA REPÚBLICA. 4. ${ }^{\mathrm{a}}$ CCR. Revista das Águas, ano 2, n. 6, junho de 2008. Disponível $\mathrm{em}:<\mathrm{http}: / /$ revistadasaguas.pgr.mpf.gov.br/edicoes-da-revista/ edicao-atual/edicoes-da-revista/edicao-atual/materias/abeleza $>$. Acesso em: 18.07.2008. 
PIERRI, N.; ÂNGULO, R. J.; SOUZA, M. C.; KIM, M. K. A ocupação e o uso do solo no litoral paranaense: condicionantes, conflitos e tendências. Desenvolvimento e Meio Ambiente, n. 13, p. 137-167, 2006.

POSSAS, M.; FAGUNDES, J.; PONDÉ, J. L. Defesa da concorrência e regulação de setores de infraestrutura em transição. ANPEC, 1998.

SANCHEZ, O. A. A privatização do saneamento. São Paulo em Perspectiva, São Paulo, v. 15, n. 1, jan./mar. 2001.

SANTOS, A. C. F. Saneamento básico: panorama jurídico e questões contundentes. Monografia - Departamento de Direito. Curso de Especialização em Direito do Estado, UFRS. Porto Alegre, 2005. Disponível em: <http://www.astecor.com.br/ materia_tecnica/ advogado/monografia_ales.doc $>$. Acesso em 22.07.2008.

SANTOS, M. M.; PAULA, L. F. Análise da política de saneamento no Brasil. In: BRASIL. Ministério da Previdência e Assistência Social. A política social em tempo de crise: articulação institucional e descentralização. Brasília: CEPAL, p. 281-354 (Série Economia e Desenvolvimento, 3), 1989.
SEMA-PR - Secretaria do Estado de Meio Ambiente e Recursos Hídricos. Monitoramento dos rios de Unidades de Conservação com bioindicadores. Curitiba: SEMA-PR, 2005.

SOUZA, C. M. N.; FREITAS, C. M.; MORAES, L. R. S. Discursos sobre a relação saneamento-saúde-ambiente na legislação: uma análise de conceitos e diretrizes. Engenharia Sanitária e Ambiental, v. 12, n. 4, p. 371-379, 2007.

SUDERHSA - SUPERINTENDÊNCIA DE DESENVOLVIMENTO DE RECURSOS HÍDRICOS E SANEAMENTO AMBIENTAL DO ESTADO DO PARANÁ. Participação pública na elaboração do Plano Estadual de Recursos Hídricos do Paraná. Disponível em: <http://www.suderhsa. pr.gov.br/modules/noticias/article.php? storyid=5>. Acesso em: 22.04.2009.

UN-HABITAT - UNITED NATIONS HUMAN SETTLEMENTS PROGRAMME. Water and sanitation in the world's cities: local actions for global goals. Londres: Earthscan, 2003. 274 p.

VAITSMAN, J. Desigualdades sociais e duas formas de particularismo na sociedade brasileira. Cadernos de Saúde Pública, v. 18, suplemento, p. 37-46, 2010. doi: 10.1590/ S0102-311X2002000700005.

Recebido em janeiro de 2010.

Aceito em setembro de 2010. Publicado em dezembro de 2010. 